\title{
O dialeto do piloto José Alves de Lima (1739-1749)
}

Susana Echeverria Echeverria*

RESUMO: Neste artigo apresentamos o estudo que desenvolvemos para identificar o dialeto de José Alves de Lima, a partir das escolhas ortográficas que esse piloto realizou ao escrever o Diario del piloto portugues, Iosê Alves de Lima que, por orden de la Corte de Portugal fue reconocer las islas de la Ascencsión y Trinidad, em las costas del Brasil; manuscrito 23047 da Biblioteca Nacional de Madrid, inédito.

PALAVRAS-CHAVE: Dialeto; José Alves de Lima; escolhas dialetais; diário, manuscrito.

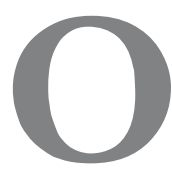

Diário do piloto português José Alves de Lima é um manuscrito do século XVIII que se encontra guardado na Sala Cervantes. Manuscritos, Incunables y Raros da Biblioteca Nacional de España, com cota Mss/23047.

Desde que o li pela primeira vez, senti grande curiosidade pela figura desse piloto. Foi por isso que solicitei informações sobre ele ao Museu da Marinha, ao Arquivo Nacional da Torre do Tombo (os dois em Lisboa) e ao Serviço de documentação da Marinha, no Rio de Janeiro. No entanto, devo dizer que em nenhum deles achei qualquer referência a esse nome.

Apesar dessas dificuldades, meu interesse pelo autor do Diário não decresceu, e optei por eu mesma investigar a sua procedência, a partir das peculiaridades que ele imprimiu à sua escrita. Comecei a procurar, nas escolhas ortográficas presentes no Diário, exemplos que me ajudassem a desco-

\footnotetext{
Universidade de Taubaté - susana.echeverria@terra.com.br .
} 
brir a variedade dialetal usada pelo seu autor. Isso porque, de acordo com Vasconcelos (1890-1892, p. 16):

\begin{abstract}
Quem possue pouca cultura litteraria escreve muitas vezes como falla, não sõ por ignorar frequentemente as regras gramaticases, como porque nessas pessoas tem mais força o habito da pronúncia do que o da escrita; ora os erros então commettidos, erros, já se vê, em relação ãs normas preestablecidas servem para o linguista, porque lhe revelam exactamente o que elle procura.
\end{abstract}

Com esse fim, vasculhei o texto à procura de marcas que adscrevessem seu autor a uma determinada região de Portugal. E foi desse modo que, na página 46v., ${ }^{1}$ deparei com a elisão do $<\mathrm{s}>$ do pronome pessoal de primeira pessoa do plural na formação nodê ; o que me pareceu que poderia indicar, seguindo a opinião de Vasconcelos, um "hábito da pronúncia" do piloto.

Ainda assim, procurei outra alternativa que justificasse esse fenômeno; essa, de ordem formal, explicaria noo $e^{u}$, ao considerar que o $<\mathrm{s}>$ seria traçado aproveitando o corpo do $<-$ d- $>$; ou seja, essa letra representaria um nexo. Nexos são, nas palavras de Núñez (1994, p. 43):

[...] uniones de dos o más letras que se producen por superposición aparente (es decir, por aproximación de una parte de dos o más letras por cuanto el trazo de la letra base del nexo sirve para formar el de la otra letra) o por inclusión de una o varias letras en la otra. ${ }^{2}$

Não obstante, a primeira interpretação pareceu-me melhor; ainda mais quando relacionei essa elisão do $<\mathrm{s}>$ com a que se observa também no dialeto andalu $r^{3}$ em que se suprime invariavelmente todo $<\mathrm{s}>$ no fim de sílaba ou de palavra..

Essa coincidência me levou a conjeturar que, pela variedade dialetal falada pelo piloto, ele procedesse do Sul de Portugal.

A partir desse achado, procurei no texto outros vestígios desse dialeto, que Leite de Vasconcelos classifica como "meridional".

1 Na Latetude e Longitude a marge Ventos NNE $4^{a}$ mais ome | nos Deos nodê boa viage e Nossa Senhora do Rozzario | eSã̃ Iozêe etc.

2 Nexos. São uniões entre duas ou mais letras que se produzem por superposição aparente (isto é, pela aproximação de uma parte de duas ou mais letras, sendo que o traço da letra base do nexo serve para formar o da outra letra) ou por inclusão de uma ou várias letras em outra. (Tradução minha.)

3 Falado no sul da Península Ibérica, desde o Algarve até a costa oriental. 


\section{Os dialetos portugueses}

Leite de Vasconcelos (1970, p. 27-44), a quem sigo neste estudo, distingue os seguintes dialetos continentais falados em Portugal (Vide ANEXO A):

Dialectes continentaux:

I. Dialecte interamnense ou d'Entre-Douro-e-Minho:

1) sous-dialecte alto-minhoto ou de l'Alto-Minho;

2) sous-dialecte baixo-minhoto ou du Baixo-Minho;

3) sous-dialecte baixo-duriense ou du Baixo-Douro;

II. Dialecte transmontano ou de Trás-os Montes:

1) sous-dialecte raiano ou de la frontière, auquel se rattache la variété d'Ermisende (Espagne);

2) sous-dialecte alto-duriense ou de l'Alto-Douro;

3) sous-dialecte occidental et central.

III. Dialecte beirão:

1) sous-dialecte alto beirão ou de la Beira-Alta;

2) sous-dialecte baixo-beirão ou de la Beira-Baixa;

3) sous-dialecte occidental ("distritos" de Coimbre et d'Aveiro).

IV. Dialecte méridional:

1) sous-dialecte estremenho ou de l'Estremadura;

2) sous-dialecte alentejano ou de l'Alentejo, auquel se rattachent la variété d'Olivença (Espagne) et l'idiome de Barrancos;

3) sous-dialecte algarvio ou de l'Algarve.

Esse mesmo filólogo assim resume os traços característicos desses dialetos:

\subsection{Dialeto "interamnense":}

1. Não distingue $<\mathrm{b}>/ \mathrm{b} / \mathrm{e}<_{\mathrm{v}}>/ \mathrm{v} /$;

2. Mantém o ditongo $<\mathrm{ou}>$;

3. Em alguns dos lugares, usa-se, para a $2^{\mathrm{a}}$ pessoa plural, <-ides $>$;

4. Denasalização de [õ], [e)];

5. Em Porto distingue-se $<$ ç $>-{ }_{-}>\mathrm{e}<\mathrm{s}>/ \mathrm{s} /-\mathrm{s}_{\mathrm{s}}>/ \mathrm{z} /$;

6. Na Borda d'Água, $<\mathrm{ch}>$ para $<\mathrm{x}>$;

7. Mantém a terminação arcaica $<-\mathrm{e}>$. 
284 ECHEVERRIA, Susana Echeverria. O dialeto do piloto José Alves de Lima (1739-1749)

\subsection{Dialeto "trasmontano":}

1. Mantém a terminação arcaica $<-a>$;

2. Preserva $<_{0}>$ dos pretéritos fortes;

3. Pretéritos em $<$-este $>$, $<$-iste $>$;

4. Mantém <ou>;

5. Não distingue $<\mathrm{b}>/ \mathrm{b} / \mathrm{de}<\mathrm{v}>/ \mathrm{v} /$;

6. No Alto-Douro, $<_{\mathrm{O}}>$ por $<\mathrm{ou}>,<\mathrm{e}>$ por $<\mathrm{eu}>$ e $[\tilde{a}]$ por [e)];

7. Distingue-se $<_{\mathrm{z}}><_{\mathrm{c}}>,<_{\mathrm{s}}>/ \mathrm{s} /-<_{\mathrm{s}}>/ \mathrm{z} / \mathrm{e}<\mathrm{ch}><_{\mathrm{x}}>$.

\subsection{Dialeto "beirão":}

1. Para $<$ ou $>$ haverá $<_{\mathrm{O}}>/<_{\mathrm{Ou}}>$;

2. $<\mathrm{u})>$ para $<\mathrm{u}>$;

3. $<\mathrm{e}>$ para $<\mathrm{a}>$;

4. $<\mathrm{e}>$ para $<\mathrm{eu}>$;

5. Confunde-se $<$ b $>$ com $<\mathrm{v}>$;

6. Distingue $<\mathrm{ch}>$ de $<\mathrm{x}>$;

7. Em alguns lugares, $<\mathrm{c}><\mathrm{z}>$ são substituídos por $<\mathrm{s}>/ \mathrm{s} /<\mathrm{s}>/ \mathrm{z} /$.

1.4 Dialeto meridional:

1. $<_{\mathrm{c}}><_{\mathrm{Z}}>$ por $<_{\mathrm{s}}>/ \mathrm{s} /<_{\mathrm{S}}>/ \mathrm{z} /$;

2. Distingue-se $<\mathrm{v}>/ \mathrm{v} /$ do $<\mathrm{b}>/ \mathrm{b} /$;

3. Rejeita ditongos;

4. No Alentejo, [y] por [1];

5. No Ribatejo, infinitivos pessoais usados como pretéritos perfeitos.

\section{O dialeto estremenho}

Depois de ler os artigos publicados por Vasconcelos na Revista Lusitana sobre os dialetos trasmontano, alentejano, algarvio e interamnense, o estudo sobre os dialetos algarvios, de Nunes (1902), e os comentários que outros filólogos fizeram sobre os dialetos de Portugal, considerei que o dialeto do piloto apresentava numerosos traços que o identificavam com o dialeto meridional, mais concretamente com o subdialeto estremenho.

Para melhor identificá-lo, incluo seguidamente os traços do subdialeto falado nas imediações de Lisboa, extraídos do artigo "Dialectos Extremenhos" (Vasconcelos, 1897-1899, p. 137-147), e os ilustrarei com exemplos do Diário de José Alves de Lima. 
1. Os ditongos decrescentes: $<\mathrm{ei}>\mathrm{e}<\mathrm{ai}>$, proclíticos, passam a $<\mathrm{e}>$ $<$ á>:

ei $>$ e fique (647), sigre (2678)

ai $>$ a mas (mais) (2284), abaxo (714)

2. A nasal final átona desnasaliza:

em $>$ e marge (6985), onte (20), viage (4939)

3. A nasal tônica é representada por til, provavelmente para evitar ditongações, que, como no caso do <-em>, em Lisboa, resultariam em [-ai) ]:

$-\mathrm{m}>\sim \quad$ ficar $\widetilde{\boldsymbol{a}}(6502)$, pore) (2530), se) (sem) (725), tambe) (2066), vi) (2802)

4. $<\mathrm{e}>$ átono final passa $\mathrm{a}<\mathrm{i}>$ :

$-\mathrm{e}>-\mathrm{i} \quad$ Recifi (3318)

5. A sílaba átona <-as > fecha-se em <-es>:

-as > -es ginades (5849), grades (1525), braces (1081)

6. Segundo Monte Carmelo (1767, p. 501-502), os falantes de Estremadura trocam as seguintes sílabas:

-rio > -iro Rozairo (4376)

7. Para esse mesmo filólogo, deve ser evitada, no dialeto estremenho, a troca de $<\mathrm{i}>$ por $<$ e $>$ e de $<$ e $>$ por $<\mathrm{i}>$ :

e > i dezobidiente (5003), disviado (1267), Espiriencia (4060), Pirigo (1062), Ricicife (3106), Rigimento (2803), Ripiquete (5729), Expidição (2357), festijou (4410), piquena (2658), Imbarcação (2823), Izeminando-ce (2817), Iz̧iminar (2804), Iclipse (1261), inda (ainda>enda>inda) (4072), Inubelado (4102), Iquinocial (6994)

i > e edioma (2313), emcorporaou (7189), emfalivelmente (3109), deferença (3128), deligencia (3249), demenubio (6000), ve zৃita (101), demenuido (6673) despedio (6089), destante (4105), latetude (7234) 
8. Esse mesmo autor diz também que os estremenhos não devem proferir tam brandamente a letra a antes de me n, que pareça dizer [...] menha, em lugar de [...] mânba; [...]:

$$
\mathrm{a}+\mathrm{m} / \mathrm{n}>\mathrm{e} \quad \text { menhã (4748) }
$$

9. No Algarve e região sul, o $<\mathrm{a}>$ fecha-se em $<\mathrm{e}>$ :

a $>$ e Berlandra (7468), Comendante (2274), menham (2377), Re 2 qao (318), Savedeira (276), empare (3807), egora (4744), viremos (3008)

10. Ele também percebe que, nessa região, o ditongo $<$ ou $>$ reduz-se $\mathbf{a}<\mathbf{0}>$ : ou $>$ o otubro (1569) ove (4203) poco (5193) troxe (4698) acalmo-nos (4179)

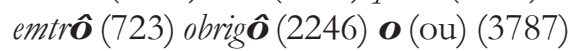

11. Pronúncia do $<\mathrm{ch}>$ como $<\mathrm{x}>$ (Barreto, 1671, p. 54 e Feijó 1739, p. 43) - segundo Monte Carmelo (1767, p.305), na conversaçâm, e ainda na ortghografia, confundem alguns Povos, particularmente os da Estremadura, a estas duas Letras:

ch $=\mathrm{x} \quad$ con $\boldsymbol{x}$ a (2114), lan $\boldsymbol{x} a$ (2352), caxoeira (3300)

12. Este dialeto mantém a primeira nasal em "conosco":

comnosco (4160)

13. No começo de palavra $<\mathrm{c}>$ ou $<$ ç $>$ substituem $<$ s $>$ :

cusseso (138)

14. Distingue-se $<\mathrm{b}>$ de $<\mathrm{v}>$.

15. Metáteses:

Com assimilação, detriminou (2558), goais (2314), gurmete (5234), preçebia (2298)

16. Síncopes:

extrior (3113), asgoas (4406)

17. Cai o $<$ s $>$ :

frecalhaõ (3978), frecos (4026), amdariamo (6518), nodê (5632/2876) 


\section{Prótese:}

asucedido (1538)

19. Segundo Vasconcelos (1970, p. 112), é comum encontrarmos os infinitivos pessoais usados como pretéritos perfeitos:

tornarmos (365)/ (2087)/ (4177)/ (6032)/ (86)/ (187)/ (241), pacarmos (5701)

\section{Sobre as terminações dos pretéritos na terceira pessoa do plural,} Vasconcelos (1970, p. 114) explica que a forma <-ão>, que é a que encontramos no Diário, era usada na Beira, e que, em Estremadura, seria <-im>.

cabira $\widetilde{\boldsymbol{o}}(718)$

\section{Conclusões}

O dialeto usado pelo piloto, no Diário, apresenta maior número de elementos registrados por Vasconcelos como marcas do dialeto meridional, e, entre os subdialetos, parece mais com o dialeto estremenho, ainda que com traços que se repetem em outros dialetos, como: $<\mathrm{ou}>$ mantido no número dous (1503), o morfema léxico para diminutivos <-nin-> em pequeninas (6187), a contração pala (5760), o morfema verbal em $<-$ ão $>$, para as terceiras pessoas do plural dos pretéritos perfeitos, e a elisão do $<\mathrm{s}>$.

A ocorrência exclusiva do morfema <-ão> para os perfeitos, fenômeno que Vasconcelos situa na Beira, e a menção do piloto de uma cidade limítrofe entre as isoglosas, Figueira, fizeram-nos pensar que o piloto poderia falar um subdialeto que misturasse elementos do Dialeto Beirão e do Dialeto Estremenho, estremenho-beirão para Cintra (apud Navas, 2001, p. 173).

Uma interpretação plausível para todas as marcas dialetais que o Diário apresenta e que as análises de Vasconcelos não mencionam estaria justificada pela distância no tempo, entre a escrita do piloto (s.XVIII) e os trabalhos sobre dialetos de Portugal do filólogo português (fim do século XIX e início do século XX). 


\section{Anexo 1}

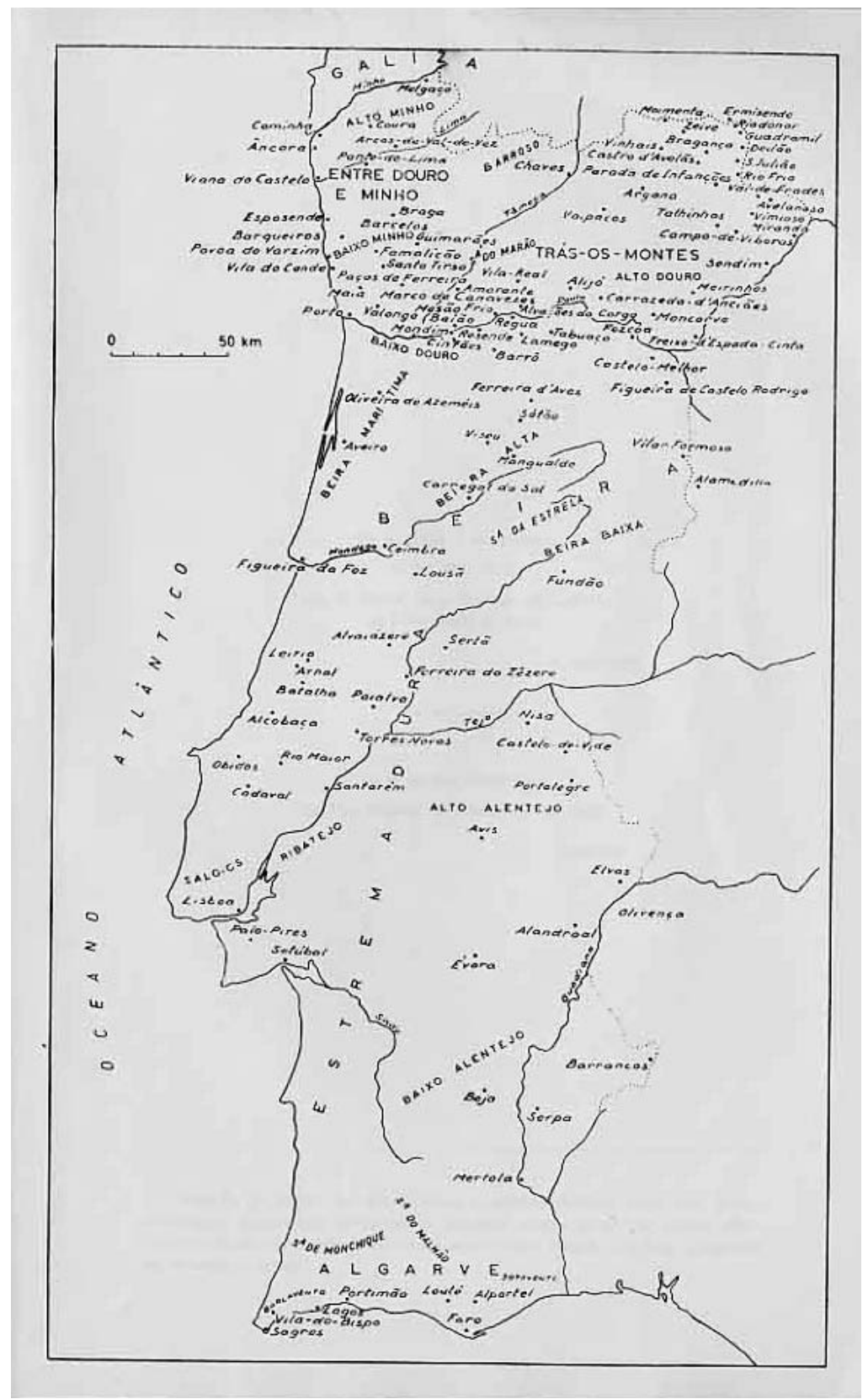

Imagem extraída da edição virtual da $\mathrm{BN}$ de Esquisse d'une dialectologie portugaise de Vasconcellos (1970, p. 172) (http://purl.pt/160/3/). 


\section{Bibliografia}

ALVES DE LIMA, J. (1759) Diario del piloto portugués José Alves de Lima. Mss/23047. Madrid: Biblioteca Nacional.

BARRETO, I. F. (1671) Ortografia da lingva portvgveza. Lisboa: Ioam Costa.

FEIJO, J. M. M. de (1734) Orthographia, ou arte de escrever, e pronunciar com acerto a lingua portuguesa para uso do excellentissimo Duque de Lafoens. Lisboa: Off. de Miguel Rodrigues.

MONTE CARMELO, L. (1767) Compendio de orthografia, com sufficientes catalogos, e novas regras... Lisboa: Off. Antonio Rodrigues Galhardo.

NAVAS, $M^{a}$ V. (2001) Relaciones entre las hablas andaluzas y portuguesas meridionales próximas. Revista de Filología Románica, v. 18, p. 171-185.

NUNES, J. (1930) Compêndio de gramática histórica portuguesa. Lisboa: Livraria Clássica Editora. --____ (1902) Dialetos algarvios. Revista Lusitana, v. VII, p. 33-55, 104-125, 244-264. Lisboa: Antiga Casa Bertrand.

NÚÑEZ, L. (1994) Manual de paleografía: Fundamentos e historia de la escritura latina hasta el siglo VIII. Madrid: Cátedra.

VASCONCELOS, J. L. (1970) Esquisse d'une dialectologie portugaise. Lisboa: Centro de Estudios Filológicos.

Portuense.

(1890-1892) Dialectos Alentejanos. Revista Lusitana,v. II, p. 115-45. Lisboa: Livraria

(1896) Dialectos alentejanos. Revista Lusitana,v. IV, p. 13-77 e 215-246. Lisboa: Antiga Casa Bertrand.

Casa Bertrand.

(1897-1899) Dialectos extremenhos. Revista Lusitana, v. V, p. 137-147. Lisboa: Antiga (1903-1905) Dialectos interamnenses. Revista Lusitana, v. VIII, p. 51-62. Lisboa: Antiga Casa Bertrand.

Casa Bertrand. (1902) Linguagens fronteiriças. Revista Lusitana, v. VII, p. 133-145. Lisboa: Antiga (1895) Notas mirandesas. Revista Lusitana, v. V, p. 195-198. Livraria Portuense. (1895) Dialectos trasmontanos. Revista Lusitana, v. III. p. 57-74. Lisboa: Livraria Portuense.

Portuense.

(1890-1892) Dialectos alemtejanos. Revista Lusitana, v. II, p. 15-45. Lisboa: Livraria

ABSTRACT: In this article we present a study developed in order to discover José Alves de Lima dialect's, using for that purpose the analysis of that Portuguese pilot's orthographical choice; which were taken from the Diario del piloto portugues, Iosê Alves de Lima que, por orden de la Corte de Portugal fue reconocer las islas de la Ascencsión y Trinidad, em las costas del Brasil; an unedited $18^{\text {th }}$ century manuscript kept at the Sala Cervantes of the Spanish Biblioteca Nacional, under number 23047.

KEYWORDS: Dialect; José Alves de Lima; orthographical choice; diary; manuscript. 